\title{
Association of Angiotensinogen (M235T) Gene Polymorphism with Blood Pressure Lowering Response to Angiotensin Converting Enzyme Inhibitor (Enalapril)
}

\author{
Kamna Srivastava ${ }^{1}$, Sudhir Chandra ${ }^{1}$, Jagriti Bhatia ${ }^{2}$, Rajiv Narang ${ }^{3}$, Daman Saluja ${ }^{1}$ \\ ${ }^{1}$ Dr. B.R. Ambedkar Centre for Biomedical Research, University of Delhi, Delhi, India; \\ ${ }^{2}$ Departments of Pharmacology and ${ }^{3}$ Cardiology, All India Institute of Medical Sciences, New Delhi, India.
}

Received, March 16, 2012; Revised, May 16, 2012; Accepted July 6, 2012, Published July 9, 2012.

\begin{abstract}
Purpose: It has been suggested that genetic backgrounds, which have an association with essential hypertension, may also determine the responsiveness to ACE inhibitor. We determined the association of angiotensinogen (M235T) gene polymorphism with essential hypertension and the relationship between polymorphism in the angiotensinogen (M235T) gene and blood pressure response to ACE inhibitor (Enalapril) in patients with essential hypertension from northern Indian subjects. Methods: 250 patients with essential hypertension and 250 normal healthy controls from Delhi and surrounding areas were recruited for the investigation. Blood pressure was recorded before and after 6 weeks of treatment with ACE inhibitors, Enalapril. Genotyping were carried out by polymerase chain reaction and Restriction fragment length polymorphism technique. Results: Statistically significant association of $\mathrm{T}$ allele was observed with essential hypertension $\left[\mathrm{x}^{2}=14.67, \mathrm{p}=0.00013\right.$, Odds ratio $=1.76(1.3-2.32)$ at $\left.95 \% \mathrm{CI}\right]$, the relative risk at 95\% CI being 1.28 (1.2-1.54). The decrease in systolic blood pressure and diastolic blood pressure after six weeks of treatment of the patients carrying TT genotype (SBP $=26 \pm 17.4 \mathrm{mmHg}, \mathrm{DBP}=14.83 \pm 7.6 \mathrm{mmHg}$ ) were greater than the groups carrying MT $(\mathrm{SBP}=3.0 \pm 7.8 \mathrm{mmHg}, \mathrm{DBP}=6.2 \pm 3.0 \mathrm{mmHg}$ ) and $\mathrm{MM}$ genotypes ( $\mathrm{SBP}=1.2 \pm 0.8 \mathrm{mmHg}, \mathrm{DBP}=0.10 \pm 12.1 \mathrm{~mm} \mathrm{Hg}$. Conclusions: The angiotensinogen (M235T) gene polymorphism is significantly associated with essential hypertension. Patients carrying TT genotype had higher blood pressure lowering response when treated with ACE inhibitor, Enalapril than those carrying $\mathrm{MM}$ and MT genotypes suggesting that the $\mathrm{T}$ allele may be a possible genetic marker for essential hypertension.
\end{abstract}

This article is open to POST-PUBLICATION REVIEW. Registered readers (see "For Readers") may comment by clicking on ABSTRACT on the issue's contents page.

\section{INTRODUCTION}

Essential hypertension is directly responsible for $57 \%$ of all stroke deaths and $24 \%$ of coronary heart disease death in India (1). Essential hypertension is a multifactorial disease associated with the interaction of genetic and environmental factors and genes contribute $20-40 \%$ of the pathogenesis of essential hypertension (2).

The renin-angiotensin system (RAS) contributes to the regulation of vascular tone, electrolyte and volume homeostasis (3), and their role in blood pressure regulation has been well established (4). Genes encoding components of RAS, including angiotensinogen, have been extensively investigated as genetic determinants of essential hypertension through genetic linkage studies, and by allelic association studies (5-6).
Three RAS gene polymorphisms- the angiotensinogen (AGT) M235T (7-13), the ACE insertion/deletion (I/D) $(10,13-19)$, and the AT1R A1166C (10, 20-21) polymorphisms - have been extensively studied. The gene that encodes angiotensinogen is found on chromosome 1q42 to 43 where a tyrosine for cytosine substitution in the second exon results in the substitution of threonine for methionine at amino acid position 235 (M235T) in the translated protein. This missense mutation of the angiotensinogen (M235T) gene has been associated with elevated

\footnotetext{
Corresponding Author: Dr. Kamna Srivastava, Molecular Cardiology Lab, Dr. B.R. Ambedkar Centre for Biomedical Research, University of Delhi, Delhi, India; E-mail: kamna_srivastava@hotmail.com
} 
levels of angiotensinogen, with 235 TT homozygotes having between $10 \%$ and $20 \%$ more plasma angiotensinogen than $235 \mathrm{MM}$ individuals (6-7). Association (case-control) studies of the M235T polymorphism in essential hypertension have yielded conflicting results. Some found linkage or association in Nigerian (22), French (21), Han Chinese (23) and Malaysian populations (24), while others have not (25-26).

Variation in patient's response to therapy is a well- known phenomenon in clinical practice. This discrepancy in patients's response most of the times lead to therapy discontinuation and/or underdosing because of poor efficacy or unwanted side effects. Genetics might be playing some role in the variability in individual response to therapy (2-7). Association between a genetic polymorphism and the response to treatment may provide insight in the pathogenetic mechanisms. The inter-individual's variation in response to the rennin-angiotensin system (RAS) blockade may partly be genetically determined. We hypothesize here that the genetic backgrounds, which have an association with essential hypertension, may also determine the responsiveness to ACE inhibitor. We chose angiotensinogen (M235T) gene polymorphism as we are aware that their role in the pathogenesis of Essential hypertension is fully elucidated. Little information is available on its possible association with the responsiveness to ACE inhibitor therapy.

Hence, present study was undertaken to determine the possible association of the genetic variants of angiotensinogen (M235T) gene polymorphism with Essential hypertension in Asian Indian subjects. Knowledge of Intergenotypic variations in angiotensinogen (M235T) gene might help to predict blood pressure response to ACE inhibitor therapy in individual patients. Hence, we have made our second objective to determine the association between polymorphism in the angiotensinogen (M235T) gene and blood pressure response to ACE inhibitor (Enalapril) in patients with Essential hypertension from northern Indian subjects.

\section{MATERIALS AND METHODS}

The three study groups are:

(1) Patients with essential hypertension to study angiotensinogen M235T gene polymorphism

The criteria of selection of patients were as follows: Patients $(\mathrm{N}=250)$ suffering from Essential hypertension was recruited from department of cardiology, AIIMS, New Delhi. Age (25-60 years), Onset (25-60 years), Systolic $\mathrm{BP}>140 \mathrm{mmHg}$ and a diastolic $\mathrm{BP}>90 \mathrm{mmHg}$ on 2 consecutive visits for those untreated, absence of secondary forms of hypertension. Subjects with a history of diabetes mellitus, renal failure and major infectious disease were excluded. They had no metabolic or endocrine disorder or any acute illness. They were not on any antihypertensive treatment and were drug naive patients.

At this stage of screening the blood were withdrawn from the patients in order to study the Association of angiotensinogen (M235T) gene polymorphism with essential hypertension.

\section{(2) Patients with essential hypertension with ACE inhibitor treatment}

Above mentioned patients (group 1) were then receiving ACE inhibitor Enalapril for six weeks thereafter and their Blood pressure response on angiotensinogen (M235T) gene polymorphism, were recorded. In our work, we limited patient's recruitment, to only those who were never treated before in order to avoid the influence of any previous treatment.

\section{(3) Controls (Normal healthy volunteers)}

Controls $(\mathrm{n}=250)$ which were age and sex matched normal healthy volunteers from the similar population group recruited from the staff of AIIMS and residents of Delhi and surrounding areas. The screening of controls was carried out by the same clinician as in patients. Blood pressures were measured in all three groups of study subjects using sphygmomanometer at least three times at an interval of five minutes in accordance with the procedures recommended by JNC VII (The Seventh Report of the Joint National Committee on Prevention, Detection, Evaluation and Treatment of High blood pressure) criteria. The subjects were seated in a chair with back support and their feet on the ground and the arm placed comfortably on a table at heart level. There was 5 min of rest in a quiet room preceding the blood pressure measurements. The appropriate-sized cuff, based on the patient's arm 
circumference was placed on the upper arm, $5 \mathrm{~cm}$ above the ulnar head. The blood Pressure measurements were always performed by the same doctor between 8.00 and 10.00 am about 24 hour after the last Enalapril dosage.

Various baseline characteristics and clinical parameters including age, gender, Body mass index, smoking and blood urea, serum creatinine and lipid profile were measured. During the study period, patient medication and dietary intake for sodium was not changed. Prior informed consent from both the study groups was obtained. An approval of study protocol by the ethical committee of AIIMS, New Delhi was obtained prior to the start of the study.

\section{Sample collection and processing}

The peripheral venous blood was drawn from the study subjects after 12 hours of fasting and packed cells were used for DNA isolation using the QIAamp ${ }^{\circledR}$ DNA Blood Mini Kit by QIAGEN®.

\begin{abstract}
Angiotensinogen (M235T) gene polymorphism Genomic DNA was amplified by polymerase chain reaction (PCR to amplify part of the exon 2 gene with primers designed to insert a half restriction endonuclease site into the product. Primers were designed using Gene Runner programme and the designed sequences were: sense-primer 5' GAT GCG CAC AAG GTC CTG TC $3^{\prime}$ and antisense primer 5' CAG GGT GCT GTC CAC ACT GGA CCC C 3'. Amplified 303 bp products of the angiotensinogen gene were digested using the Psyl (Fermentas life sciences) and the resultant fragments resolved on $2.7 \%$ agarose gel to give 2 fragments, the longer fragment, $279 \mathrm{bp}$ and the shorter $24 \mathrm{bp}$. Individuals homozygous for allele, ie MM, a 303bp band appeared on the gel, homozygous TT (only a single 279-bp band appeared on the gel) and heterozygous MT (303-bp band and a 279-bp band appeared on the gel).
\end{abstract}

\section{STATISTICAL ANALYSIS}

All computations were carried out with STATA program, version 8 . Results are expressed as mean \pm sd (standard deviation). Sample size was adequate for the present study determined by using standard statistical method at the ratio of 1:1 for case control groups, at the significance level of 0.05 at power $80 \%$ on the basis of prevalence of minor alleles referred from previous studies $(6,27)$. Chi-square goodness of fit was used to verify the agreement of observed genotype frequencies with those expected (Hardy-Weinberg equilibrium). Difference between genotype groups were tested with analysis of variance (ANOVA) using Bonferroni's method for multiple comparisons between genotype classes. The multilinear stepwise regression was made to assess the factors responsible for the reduction of blood pressure. $\mathrm{P}$ $<0.05$ was considered statistically significant.

Calculation of mean arterial pressure is done by the formula given below:

\section{Equation: $\mathrm{MAP}=[(2 \mathrm{x}$ diastolic $)+$ systolic $] / 3$}

Where, diastole counts twice as much as systole because $2 / 3$ of the cardiac cycle is spent in diastole. The usual range of MAP is 70-110 and an MAP of about 60 is necessary to perfuse coronary arteries, brain and kidneys.

\section{RESULTS}

Baseline characteristics of the study subjects A total of 250 hypertensive patients and 250 controls were enrolled in our study. Average age of the controls and patients was comparable. Number of male volunteers was comparable to female in both the study subjects. The mean values of body mass index (BMI), heart rate, different biochemical parameters and Systolic and diastolic blood pressures of study subjects were comparable in both the study subjects (Table 1).

Distribution of genotypes and alleles of angiotensinogen (M235T) gene polymorphism in the study subjects

The distribution of genotypes (MM, MT and TT) in the controls and patients did not differ significantly from that expected under HardyWeinberg equilibrium. In the total of 250 patients, the MM genotype was observed in 112 patients, the MT genotype was observed in 120 patients and the TT genotype in 18 patients. The observed genotypes in controls were $154 \mathrm{MM}, 90$ MT, 6TT genotype. The allele frequencies in patients were found to be 0.69 and 0.31 for $\mathrm{M}$ and $\mathrm{T}$ allele respectively whereas 0.80 and 0.20 for $\mathrm{M}$ and $\mathrm{T}$ in controls. We found significant association of angiotensinogen genotypes $(\mathrm{MT}+\mathrm{TT})$ with essential hypertension as the observed difference in genotypes between the controls and patients was statistically significant. $\left[\mathrm{x}^{2}=13.9, \mathrm{p}=0.00016\right.$, Odds ratio $=1.97(1.35$ 2.85 ) at $95 \% \mathrm{CI}]$, the relative risk at $95 \% \mathrm{CI}$ was 
1.3 (1.15-1.6) . Statistically significant association of $\mathrm{T}$ allele was observed with essential hypertension $\left[x^{2}=14.67, p=0.00013\right.$, Odds ratio $=1.76(1.3-2.32)$ at $95 \% \mathrm{CI}]$, the relative risk at 95\% CI being 1.28 (1.2-1.54) (Table 2). Odds ratio and relative risk adjusted for age and sex in both genotypes and alleles.

Comparison of Reductions of Blood pressure among different genotypes of angiotensinogen (M235T) gene in the patients receiving ACE inhibitor Enalapril

The observed changes in systolic and diastolic blood pressure were analyzed to determine their association with genotypes at the angiotensinogen gene locus. There was statistically significant reduction in systolic blood pressure in patients with MM, MT and TT genotypes, $1.2 \pm 0.8 \mathrm{mmHg}$, $3.0 \pm 7.8 \mathrm{mmHg}, 26 \pm 17.4 \mathrm{mmHg}$, respectively $(\mathrm{p}<0.0001)$ when treated with ACE inhibitor, Enalapril for a duration of 6 weeks. Similarly, there was significant reduction in diastolic blood pressure in patients with MM, MT and TT genotypes, ie, $0.10 \pm 12.1 \mathrm{mmHg}, 6.2 \pm 3.0 \mathrm{mmHg}$ and $14.83 \pm 7.6 \mathrm{mmHg}$, respectively $(\mathrm{p}<0.0001)$ when treated with ACE inhibitor, Enalapril. The decrease in systolic blood pressure and diastolic blood pressure after six weeks of treatment of the patients carrying TT genotype $(\mathrm{SBP}=26 \pm 17.4$ $\mathrm{mmHg}, \mathrm{DBP}=14.83 \pm 7.6 \mathrm{mmHg}$ ) were greater than the groups carrying MT $(\mathrm{SBP}=3.0 \pm 7.8$ $\mathrm{mmHg}$, DBP $=6.2 \pm 3.0 \mathrm{mmHg}$ ) and $\mathrm{MM}$ genotypes $(1.2 \pm 0.8 \mathrm{mmHg}, \mathrm{DBP}=0.10 \pm 12.1$ $\mathrm{mmHg}$.

The mean arterial pressure (MAP) before Enalapril treatment in patients with three genotypes ie MM, MT and TT were comparable $(\mathrm{p}=0.06)$. In our study, the mean arterial pressure in patients with TT genotypes (116.9 \pm 15.4 $\mathrm{mmHg}$ ) was higher than the normal range of 70 $110 \mathrm{mmHg}$ and there was significantly greater reduction in MAP after treatment with Enalapril as compared to patients with MT $(p=0.03)$ and MM genotypes $(\mathrm{p}=0.001) \quad($ Table 3$)$.

\begin{tabular}{llll}
\hline Table 1. Baseline characteristics of the study subjects. & & \\
\hline Parameters & Patients & Controls & p value \\
\hline Number $(\mathrm{N})$ & 250 & 250 & \\
Sex (M/F) & $164 / 86$ & $170 / 80$ & 0.85 \\
Age (years) & $52.2 \pm 5.8$ & $49.7 \pm 11.1$ & 0.21 \\
BMI, $(\mathrm{Kg} / \mathrm{m} 2)$ & $18.58 \pm 2.9$ & $18.6 \pm 3.4$ & 0.95 \\
Heart Rate, $(\mathrm{Beats} / \mathrm{min})$ & $74.5 \pm 10.6$ & $71.8 \pm 5.8$ & 0.86 \\
Blood glucose (mg/dl) & $92.54 \pm 18.3$ & $91.9 \pm 14.3$ & 0.78 \\
Blood Urea (mg/dl) & $20.7 \pm 4.3$ & $18.8 \pm 3.7$ & 0.63 \\
Serum Creatinine & $0.98 \pm 0.2$ & $0.96 \pm 0.25$ & 0.72 \\
LDL cholesterol (mg/dl) & $86.3 \pm 21.5$ & $92.3 \pm 27.3$ & 0.11 \\
HDL cholesterol (mg/dl) & $41.4 \pm 6.2$ & $38.3 \pm 6.2$ & 0.08 \\
Triglyceride (mg/dl) & $167.1 \pm 30.3$ & $169.9 \pm 20$ & 0.78 \\
Total cholesterol (mg/dl) & $149 \pm 45$ & $158 \pm 44$ & 0.08 \\
Systolic blood pressure(SBP) $\mathrm{mm} \mathrm{Hg,}$ & $152.0 \pm 13.0$ & $120 \pm 3.3 *$ & 0.0001 \\
Diastolic blood pressure(DBP) $\mathrm{mm} \mathrm{Hg,}$ & $94.6 \pm 8.7$ & $80.6 \pm 2.8^{*}$ & 0.0001 \\
\hline
\end{tabular}

*Significant difference between groups.

\begin{tabular}{|c|c|c|c|c|c|c|}
\hline \multirow[t]{2}{*}{ Subject } & \multicolumn{3}{|c|}{ Genotypes* } & \multirow[t]{2}{*}{ Allele Frequency** } & \multirow{2}{*}{$\mathrm{M}$} & \multirow[b]{2}{*}{$\mathrm{T}$} \\
\hline & MM(\%) & MT(\%) & TT(\%) & & & \\
\hline Controls $(\mathrm{n}=250)$ & $154(61.60)$ & $90(36.0)$ & $6(2.4)$ & $\mathrm{x}^{2}=2.94, \mathrm{p}>0.05(\mathrm{DF}=1)$ & 0.8 & 0.2 \\
\hline Patients $(\mathrm{n}=250)$ & $112(44.8)$ & $120(48.0)$ & $18(7.2)$ & $\mathrm{x}^{2}=3.49, \mathrm{p}>0.05(\mathrm{DF}=1)$ & 0.69 & 0.31 \\
\hline \multicolumn{7}{|c|}{ 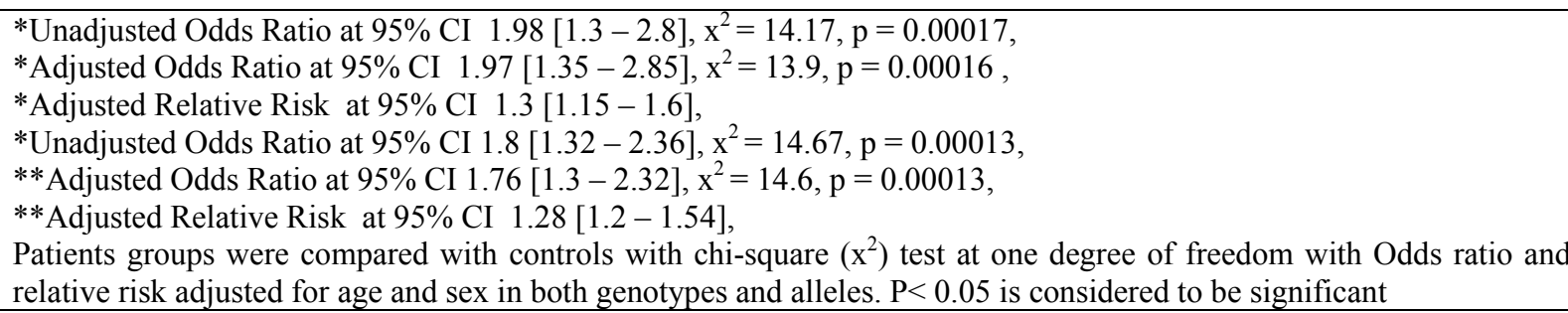 } \\
\hline
\end{tabular}




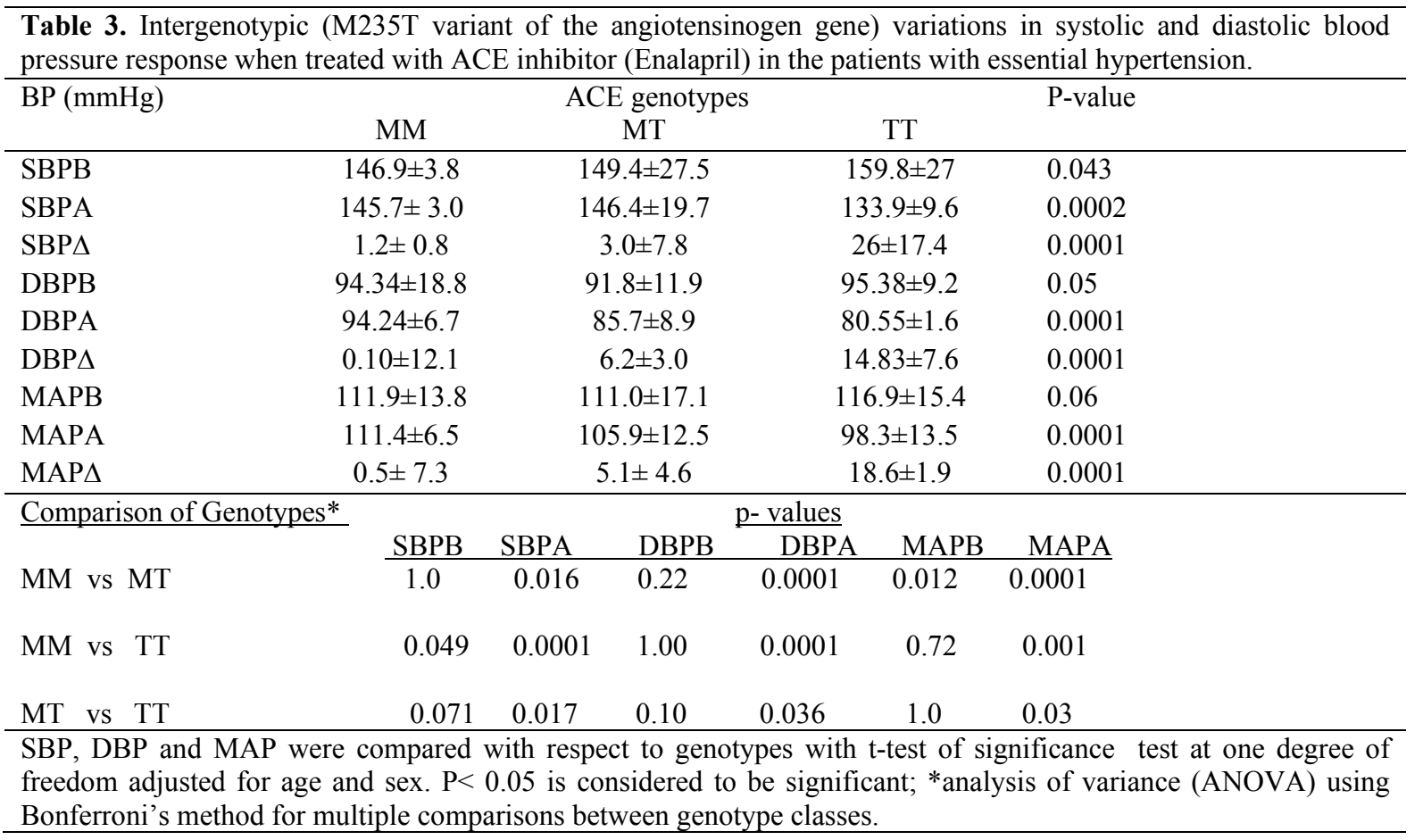

\section{DISCUSSION}

Several studies have reported association between essential hypertension and angiotensinogen (M235T) gene polymorphism. These associations were reported in the French (21), Han Chinese (23), and Malaysian populations (24), whereas others have found no association (25-26). In German population, Ortlepp et al. (28) reported that the effect of angiotensinogen (M235T) gene polymorphism on blood pressure regulation is detectable very early in life far before the onset of arterial hypertension. In Japanese populations (29-30), some studies found a positive association of TT genotype with essential hypertension. A study from India, reported in small sample size was lacking the association of this gene polymorphism with essential hypertension (31). We conducted a case-control study in North Indian population to find any association between M235T gene polymorphism and essential hypertension. In our study, a codominant pattern of inheritance was seen in both the study subjects as the genotype frequencies in both groups were all in accordance with the Hardy-Weinberg equilibrium. Results from our study have shown the distribution of M235T genotypes among patients in the order of MT $>M M>T T$, which was similar to French (21) and East Anglians (32) and quite different from the Asian populations reported ie, Han Chinese (23) and Japanese (25). The frequency of $\mathrm{T}$ allele among controls in our study, which was 0.20 , is 2 times lower than the study in French population $(6,21)$ and approximately three times lower than Japanese (30) population. Multivariate logistic regression analysis (regressed for age and sex) revealed that individuals with the " $\mathrm{T}$ " allele were at 1.8 times higher odds $\left[1.76(1.3-2.32)\right.$ at $95 \% \mathrm{CI}, \mathrm{X}^{2}=14.6$, $\mathrm{p}=0.00013]$ to develop Essential hypertension. Our study showed a higher Odds Ratio (O.R.) of $1.76(95 \% \mathrm{CI}, 1.3-2.32)$ compared to a recent meta-analysis of 12 studies in the Whites which indicated that T235 is associated with a $20 \%$ increase risk of hypertension (O.R. $=1.22,95 \%$ CI, 1.10-1.29) (9). The relative risks for hypertension are 1.3 for subjects carrying the TT phenotype and 1.28 for those having allele $\mathrm{T}$ of the angiotensinogen (M235T) gene polymorphism. This study provides the normal distribution of the genotypes and alleles in this polymorphism among Asian Indians from Northern region of India which can be used as the baseline data to elucidate the contribution of this polymorphism in the disease state. It suggests that genetic factors have an important role to play in the etiology of Essential hypertension.

There is general agreement that the $\mathrm{T}$ allele of angiotensinogen (M235T) gene is associated with increased plasma angiotensinogen level (6-7). 
Angiotensin-converting-enzyme (ACE) inhibitors are recommended for managing cardiovascular diseases, such as hypertension and heart failure (33). However, there is substantial variability in individual responses to these agents. For example, fewer than $50 \%$ of hypertensive patients achieve adequate blood pressure control with ACE inhibitor monotherapy (34). An increasing number of studies have indicated that patients from different ethnic groups of population have different responses to ACE inhibitors. Heterogeneity in the individual blood pressure response to ACE inhibitor therapy still represents an obstacle in the treatment of Essential hypertension. Comparison of genotypes has shown a significant difference in the frequencies of angiotensinogen (M235T) gene polymorphisms differ significantly by race $(6,22,24,30)$. Thus, it is possible that the ethnic diversity in genotypes contributes to the observed variability in ACE inhibitor responses among races, although no data pertaining to this hypothesis are available.

Hingorani et al. (26) have reported association of $235 \mathrm{~T}$ allele associated with greater blood pressure response in patients essential hypertension when treated with ACE inhibitor Enalapril for a duration of 4 weeks. They further added that blood pressure response was dependent on angiotensinogen genotype in the Caucasians with captopril, enalapril, lisinopril and perindopril. In a separate study, Hingorani et al. (32) have concluded that the angiotensinogen M235T gene polymorphism is not a marker for blood pressure level in these East Anglian subjects. Mondorf et al. (35) found no relationship between the polymorphism and blood pressure response to an ACE inhibitor (captopril) in white subjects. This inconsistency in results might be explained by the genetic and environmental heterogeneity among different ethnic groups, and differences in ACE inhibitors (36) used and study sample size. This inconsistency in results led us to determine the relationship between the Angiotensinogen M235T gene polymorphism and blood pressure response to an ACE inhibitor (Enalapril) in an appropriate sample size of 250 patients from North India. To the best of our knowledge, no such study exists in Asian Indian context.

The major finding of our work is the significantly greater blood pressure fall observed in carriers of genotype TT compared with individuals with MT and MM genotypes in systolic as well as diastolic blood pressures $(\mathrm{p}<0.0001)$. Our results are in accordance with the study conducted by Hingorani et al. (26) in which they have reported association of $235 \mathrm{~T}$ allele associated with greater blood pressure response in 125 subjects with previously untreated essential hypertension when treated with ACE inhibitor Enalapril for a duration of 4 weeks. However, in our study subjects, the number of patients was comparatively higher than previously studies reported so far $(32,35)$ and we have also reported a significant association of angiotensinogen (M235T) gene with essential hypertension. We have also determined the mean arterial pressure in the study subjects. The mean arterial pressure represents the average arterial pressure throughout the cardiac cycle, and is the force that drives blood through the vasculature. In our study, the mean arterial pressure in patients with TT genotypes was higher than the normal range of $70-110 \mathrm{~mm} \mathrm{Hg}$ and there was significantly greater reduction in MAP after treatment with Enalapril as compared to patients with MT ( $p=$ $0.03)$ and $M M$ genotypes $(p=0.001)$. Our study can provide a baseline data to predict response to $\mathrm{ACE}$ inhibitors in a patient population.

\section{CONCLUSION}

We have found that the individuals with the $\mathrm{T}$ allele of the angiotensinogen (M235T) gene were strongly associated with essential hypertension in northern Indians. Our findings also provide the direct evidence of gene disease association of this region and higher predisposition of Asian Indians to the essential hypertension. Our findings also suggest that angiotensinogen (M235T) gene polymorphisms may help in predicting the intergenotypic variations in blood pressure response to ACE inhibitor, Enalapril in patients with essential hypertension in northern Indian subjects, also it can provide a baseline data to predict response to ACE inhibitors in a patient population. Patients carrying TT genotype had higher blood pressure lowering response when treated with ACE inhibitor, Enalapril than those carrying MM and MT genotypes, suggesting that $\mathrm{T}$ allele may be the biomarker of patients with essential hypertension. The effect of different angiotensinogen (M235T) genotypes on ACE inhibitor therapy may offer some clinical clues to the individual therapy for essential hypertension. This information will be of immense use in personalization of drug therapy to patients with hypertension based on the angiotensinogen (M235T) genotypes. 


\section{ACKNOWLEDGEMENTS}

This work is supported by grant (DST/WOSA/LS-37) from Department of Science and Technology, India to Dr. Kamna Srivastava.

\section{REFERENCES}

1. Gupta R. Trends in hypertension epidemiology in India. J Hum Hypertens, 18:73-78, 2004.

2. Ward, R. in Hypertension : Pathophisiology, Diagnosis and Management (eds Laragh, J. H. \& Brenner, B. M.) 81-100 (Raven Press, New York, 1990).

3. Hall JE, Guyton AC. Control of sodium excretion and arterial pressure by intrarenal mechanisms and the renin-angiotensin system. In: Laragh $\mathrm{JH}$, Brenner BM (eds). Hypertension Pathophysiology, Diagnosis and Management. Raven Press: New York, pp 1105-1130, 1990

4. Inagami T. The rennin angiotensin system. Essays Biochem, 28:147-164, 1994.

5. Thiel B, Weder AB. Genes for Essential Hypertension: Hype, Help, or Hope? J Clin Hypertens (Greenwich), 2:187-193, 2002.

6. Jeunemaitre X, Soubrier F, Kotelevtsev YV, Lifton RP, Williams CS, Charru A et al. Molecular basis of human hypertension: role of angiotensinogen. Cell, 71:169-180, 1992.

7. Brand, E., Chatelain, N., Paillard, F., Tiret, L., Visvikis, S., Lathrop, M. et al. Detection of putative functional angiotensinogen (AGT) gene variants controlling plasma AGT levels by combined segregation-linkage analysis. Eur J Hum Genet, 10:715-723, 2002.

8. Staessen JA, Kunzetsova T, Wang JG, Emelianov D, Vlietinck R, Fagard R. M235T angiotensinogen gene polymorphism and cardiovascular renal risk. J Hypertens, 17:9-17, 1998.

9. Kunz R, Kreutz R, Beige J, Distler A, Sharma AM. Association between the angiotensinogen 235T-variant and essential hypertension in whites: a systematic review and methodological appraisal. Hypertension, 30:1331-1337, 1997.

10. Thomas GN, Young RP, Tomlinson B, Woo KS, Sanderson JE, Critchley JAJH. Reninangiotensinaldosterone system gene polymorphisms and hypertension in Hong Kong Chinese. Clin Exp Hypertens, 23:87-97, 2000.

11. Chiang FT, Hsu KL, Tseng CD, Hsiao WH, Lo $\mathrm{HM}$, Chern TH et al. Molecular variant M235T of the angiotensinogen gene is associated with essential hypertension in Taiwanese. J Hypertens, 15:607-611, 1997.

12. Sheu WH, Lee WJ, Jeng CY, Young MS, Ding YA, Chen YT. Angiotensinogen gene polymorphism is associated with insulin resistance in nondiabetic men with or without coronary heart disease. Am Heart J, 136:125-131, 1998.
13. Young RP, Chan JCN, Critchley JAJH, Poon E, Nicholls G, Cockram CS. Angiotensinogen T235 and ACE insertion/deletion polymorphism associated with albuminuria in Chinese type 2 diabetic patients. Diabetes Care, 21:431-437, 1998.

14. Staessen JA, Wang JG, Ginocchio G, Petrov V, Saavedra AP, Soubrier F et al. The deletion/insertion polymorphism of the angiotensin converting enzyme gene and cardiovascular-renal risk. J Hypertens, 15:15791592, 1997.

15. Sharma P. Meta-analysis of the ACE gene in ischaemic stroke. J Neurol Neurosurg Psychiatry, 64:227-230, 1998.

16. Katsuya T, Horiuchi M, Chen YDI, Koike G, Pratt RE, Dzau VJ et al. Relation between deletion polymorphism of the angiotensin-converting enzyme gene and insulin resistance, glucose intolerance, hyperinsulinemia and dislipidemia. Arterioscler Thromb Vasc Biol, 15:779-782, 1995.

17. Chiu KC, McCarthy JE. The insertion allele at the angiotensin I-converting enzyme gene locus is associated with insulin resistance. Metabolism, 46:395-399, 1997.

18. Panahloo A, Andres C, Mohamed-Ali V, Gould MM, Talmud P, Humphries SE et al. The insertion allele of the ACE gene I/D polymorphism: a candidate gene for insulin resistance? Circulation, 92:3390-3393, 1995.

19. Cong ND, Hamaguchi K, Saikawa T, Hara M, Sakata T. The I/D polymorphism of angiotensinconverting enzyme gene but not the angiotensinogen gene is associated with insulin response to oral glucose in Japanese. Proc Soc Exp Biol Med, 220:46-51, 1999.

20. Bonnardeaux A, Davies E, Jeunemaitre X, Fery I, Charru A, Clauser E et al. Angiotensin II type 1 receptor gene polymorphisms in human essential hypertension. Hypertension, 24:63-69, 1994.

21. Tiret L, Blanc H, Ruidavets JB, Arveiler D, Luc $\mathrm{G}$, Jeunemaitre $\mathrm{X}$ et al. Gene polymorphisms of the renin-angiotensin system in relation to hypertension and parental history of myocardial infarction and stroke: the PEGASE study. J Hypertens, 16:37-44, 1998.

22. Rotimi C, Cooper R, Ogunbiyi O, Morrison L, Ladipo M, Tewksbury D et al. Hypertension, serum angiotensinogen and molecular variants of the angiotensinogen gene among Nigerians. Circulation, 95:2348-2350, 1997.

23. Ji LD, Zhang LN, Shen P, Wang P, Zhang YM, Xing $\mathrm{WH}$ et al. Association of angiotensinogen gene M235T and angiotensin-converting enzyme gene I/D polymorphisms with essential hypertension in Han Chinese population: a metaanalysis. J Hypertens, 28:419-28, 2010.

24. Say YH, Ling KH, Duraisamy G, Isaac S, Rosli R. Angiotensinogen M235T gene variants and its association with essential hypertension and plasma 
renin activity in Malaysian subjects: a case control study. BMC Cardiovasc Disord, 5:7, 2005.

25. Kishimoto T, Suyama A, Osaki Y, Miyamoto T, Igarashi A, Okamoto $\mathrm{M}$ et al. A Molecular Variant of the Angiotensinogen Gene and Hypertension in a Case-Control Study in Japanese. Yonago Acta medica, 44:79-83, 2001.

26. Hingorani AD, Jia H, Stevens PA, Hopper R, Dickerson JEC, Brown MJ. Renin-angiotensin system gene polymorphisms influence blood pressure and the response to angiotensin converting enzyme inhibition. J Hypertens, 13(pt II):1602-1609, 1995.

27. Srivastava K, Sundriyal R, Meena PC, Bhatia J, Narang R, Daman Saluja D. Association of Angiotensin Converting Enzyme (Insertion/Deletion) Gene Polymorphism with Essential Hypertension in Northern Indian Subjects. Genetic Testing and Molecular Biomarkers, 16:174-177, 2012.

28. Ortlepp JR, Metrikat J, Mevissen V, Schmitz F, Albrecht $\mathrm{M}$, Maya-Pelzer $\mathrm{P}$ et al. Relation between the angiotensinogen (AGT) M235T gene polymorphism and blood pressure in a large, homogeneous study population. J Hum Hypertens, 17:555-564, 2003.

29. Kamitani A, Rakugi H, Higaki J, Yi Z, Mikami H, Miki $T$ et al. Association analysis of a polymorphism of the angiotensinogen gene with essential hypertension in Japanese. J Hum Hypertens, 8:521-524, 1994.
30. Nishiuma S, Kario $K$, Kayaba $K$, Nagio $N$, Shimada K, Matsuo $\mathrm{T}$ et al. Effect of the angiotensinogen gene Met235 $\rightarrow \mathrm{Thr}$ variant on blood pressure and other cardiovascular risk factors in two Japanese populations. J Hypertens, 13:717-722, 1995.

31. Nair KG, Shalia KK, Ashavaid TF, Dalal JJ. Coronary heart disease, hypertension, and angiotensinogen gene variants in Indian population. J Clin Lab Anal, 17:141-147, 2003.

32. Hingorani AD, Sharma P, Jia H, Hopper R, Brown MJ. Blood Pressure and the M235T Polymorphism of the Angiotensinogen Gene. Hypertension, 28:907-911, 1996.

33. The sixth report of the Joint National Committee on Prevention, Detection, Evaluation, and Treatment of High Blood Pressure. Arch Intern Med, 157:2413-46, 1997.

34. Materson BJ, Reda DJ, Cushman WC. Department of Veterans Affairs single-drug therapy of hypertension study. Revised figures and new data. Department of Veterans Affairs Cooperative Study Group on Antihypertensive Agents. Am J Hypertens, 8:189-192, 1995.

35. Mondorf UF, Russ A, Wiesemann A, Herrero M, Oremek G, Lenz T. Contribution of angiotensin I converting enzyme gene polymorphism and angiotensinogen gene polymorphism to blood pressure regulation in essential hypertension. Am J Hypertens, 11:174-183, 1998.

36. Johnson JA. Ethnic Differences in Cardiovascular Drug Response : Potential Contribution of Pharmacogenetics. Circulation, 118:1383-1393, 2008. 